\title{
Coordination Polymers of Small Cyano Anions
}

\author{
Stuart R. Batten*, Glen B. Deacon, Keith S. Murray, and David R. Turner
}

\begin{abstract}
Small cyano anions, and their derivatives, have proved to be remarkably versatile building blocks for coordination polymers. They have led to magnetically ordered materials, structures with new entangled motifs or novel topologies, and a significant structural diversity, including polymorphism, induced by subtle changes in anion, cation, co-ligands, preparative conditions, or even desolvation.
\end{abstract}

Keywords: Coordination polymers $\cdot$ Crystal engineering $\cdot$ Magnetic properties $\cdot$ Small cyano anions

Small cyano anions (SCAs; Fig. 1) have a long history, with seminal contributions in previous decades from the groups of Kohler ${ }^{[1]}$ and Kohout, Hvastijova and colleagues. ${ }^{[2]}$ However, outside of these groups this fascinating family of anions was wholly ignored, and in recent years we have been revisiting them for a whole range of applications, including coordination polymers, single molecule magnets, and ionic liquids. ${ }^{[3,4]}$

The anions have a number of properties which make them attractive for coordination polymers. Obviously they possess a negative charge (which can lead to neutral or even anionic networks), and the charge is also delocalised (with several resonance forms possible). The anions are small, leading to e.g. short magnetic pathways, and are very simple to synthesise on a large scale. The coordinating functionalities are arranged in a divergent fashion, necessary for coordination polymers, and they often contain a range of different coordinating atoms, which may lead to heterometallic networks.

The first anions to be reinvestigated were tricyanomethanide $\left(\mathrm{tcm}, \mathrm{C}(\mathrm{CN})_{3}^{-}\right)$ and dicyanamide $\left(\mathrm{dca}, \mathrm{N}(\mathrm{CN})_{2}^{-}\right) .^{[3]}$ The simple binary $\left[\mathrm{M}(\mathrm{tcm})_{2}\right]$ compounds $(\mathrm{M}=$ divalent transition metal) contain two interpenetrating rutile-related three-dimension- al (3D) networks (Fig. 2a). ${ }^{[5,6]}$ The metals are coordinated to six tcm anions in an octahedral arrangement, while the tcm anions each coordinate to three metals, one metal each for the three nitrile arms of the anion. The $\alpha-\left[\mathrm{M}(\mathrm{dca})_{2}\right]$ analogues also show rutile-related networks, with the dca anion coordinating through both nitrile groups and the amide nitrogen. ${ }^{[7-9]}$ The smaller dca anion, however, creates a less spacious network and thus interpenetration does not occur (Fig. 2b). The smaller intermetallic distances do, however, lead to magnetic ordering, with critical temperatures as high as $47 \mathrm{~K}$ for the $\mathrm{Cr}$ antiferromagnet. ${ }^{[10]} \mathrm{By}$ contrast, no such ordering is observed for the tcm family, with the exception of some evidence of ordered phases at very low temperatures for $\mathrm{Cr}, \mathrm{Mn}$ and $\mathrm{Cu} .^{[11-13]}$

Reaction of transition metals with both anions leads to the $[\mathrm{M}(\mathrm{dca})(\mathrm{tcm})]$ series of compounds. ${ }^{[14]}$ Structurally, these are a compromise between the interpenetrating and non-interpenetrating rutile networks of the 'parent' $\left[\mathrm{M}(\mathrm{SCA})_{2}\right]$ species. They form single, self-penetrating networks with a topology similar to, but different from, the rutile network (Fig. 2c). Notably, the magnetic properties are also a compromise they show long range magnetic ordering, but at lower critical temperatures than the $\left[\mathrm{M}(\mathrm{dca})_{2}\right]$ analogues.

Following these observations of magnetic ordering in the dca coordination polymers, the anion began to attract significant attention. Ultimately, the $\mu_{3}$ coordination mode observed in the $\alpha-\left[\mathrm{M}(\mathrm{dca})_{2}\right]$ species proved to be very important for the magnetic ordering. Unfortunately, however, the $\mu_{2}$ bridging mode, where the anion bridges through only the nitrile nitrogen atoms and the amide nitrogen remains unbound, was found to be the most common coordination mode of the anion. Nonetheless, a number of structurally interesting coordination polymers followed.[3] A beta polymorph for the $\left[\mathrm{M}(\mathrm{dca})_{2}\right]$ compounds was discovered, containing $(4,4)$ sheets of tetrahedral metal ions (Co, Zn) bridged by bent $\mu_{2}$-dca connectors. ${ }^{[15]}$ The use of

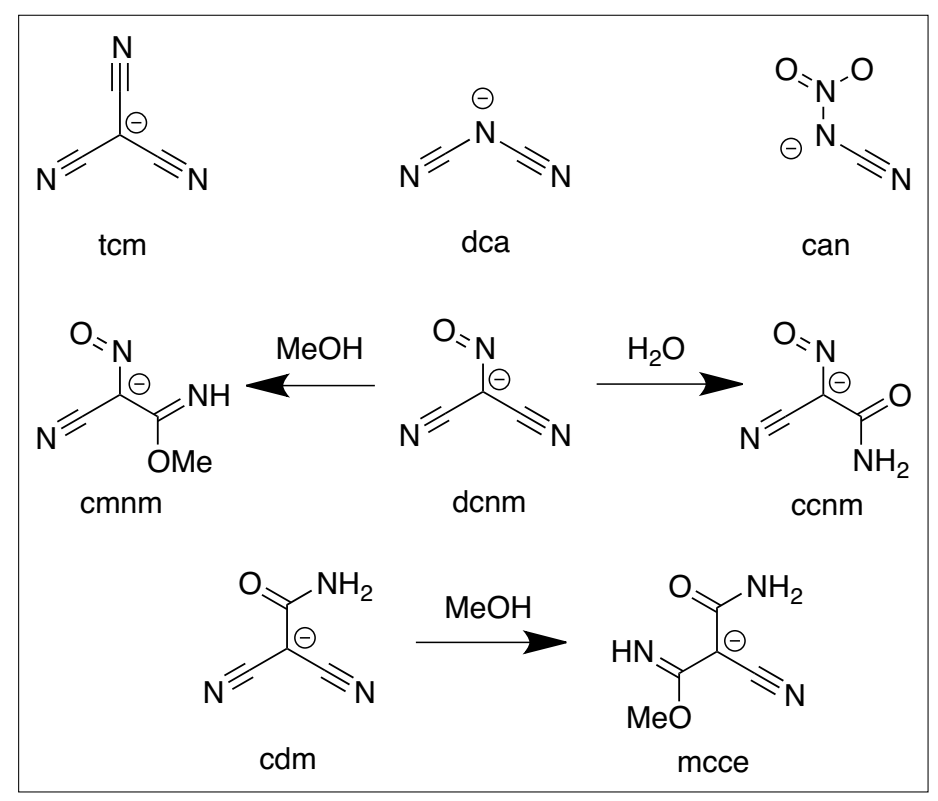

Fig. 1. A selection of small cyano anions, and their derivatives. 


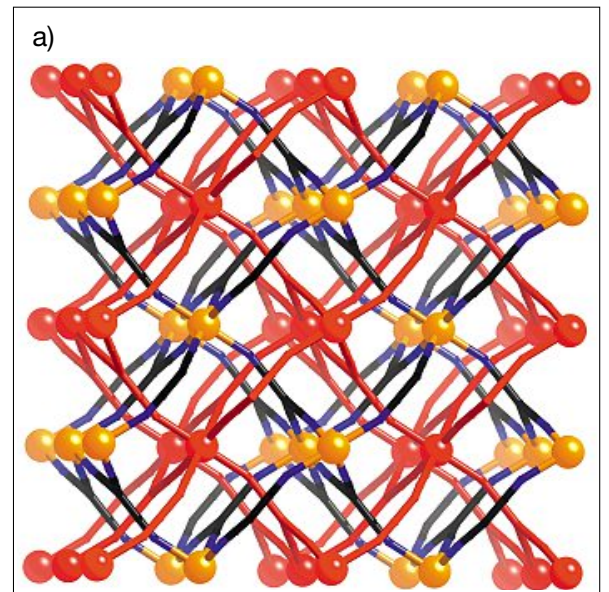

b)

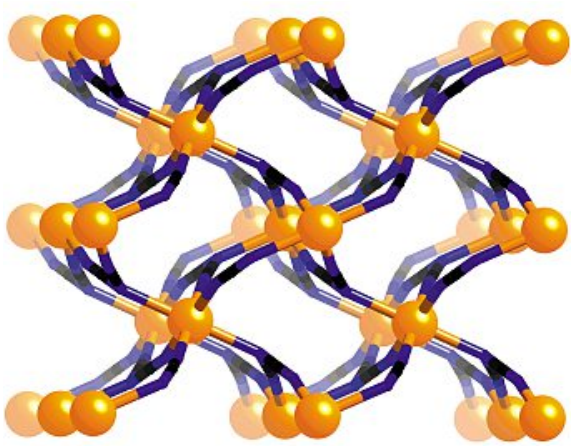

c)

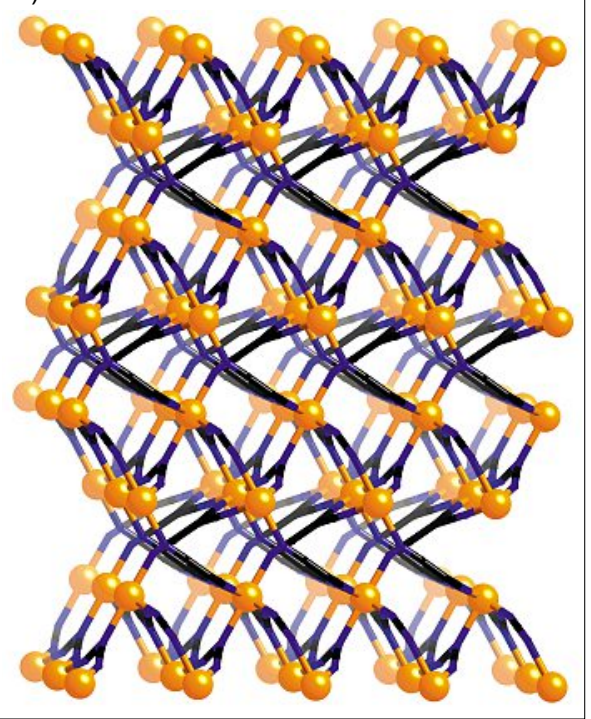

Fig. 2. (a) The two interpenetrating rutile nets of $M(t c m)_{2}$. (b) The single rutile net of $M(d c a)_{2}$. (c) The single self-penetrating net of $M(d c a)(t c m)$.

terminal and bridging co-ligands gave a route to a great variety of new structures; notable examples from our own work include one-dimensional (1D) tube-like polymers with 2-aminopyrimidine, ${ }^{[16]}$ and two-dimensional $(2 \mathrm{D})(4,4)$ sheets or interpenetrating $\alpha$-Po like networks with linear pyridyl donor bridges such as pyrazine and 4,4'-bipyridine (4,4'-bipy). [17-19]

The variety of structures that can be obtained is perhaps best illustrated by the products of the reactions of $\mathrm{Cu}^{\mathrm{I}}$, dca or tcm, and bridging coligands. With tcm and hexamethylenetetramine, 4,4'-bipy or 1,2-bis(4-pyridyl)ethene 2D (4,4) sheets are obtained, containing $\mu_{2}$-tcm anions and co-ligands.[20] Although the sheets themselves are similar, they use different packing strategies to fill the spaces created by their windows (interdigitation, intercalation, interpenetration). When tcm is replaced with dca, a different series of network structures is obtained despite the dca anion adopting a similar bridging mode to tcm. ${ }^{[21]}$ Furthermore, polymorphs and pseudopolymorphs are formed. With 4,4'-bipy an initial kinetic phase of 1D ladders is formed; after a few days the yellow-orange dichroic crystals are replaced by dark red crystals of a more thermodynamically stable phase. This second phase contains thick $2 \mathrm{D}$ sheets showing $2 \mathrm{D} \rightarrow 3 \mathrm{D}$ parallel interpenetration. While structurally very different, the only difference in the formulae of these two compounds is the number of solvent molecules present in the product. With the more extended 1,2-bis(4-pyridyl)ethene true polymorphs are formed, one consisting of 2D $(4,4)$ sheets showing twofold $2 \mathrm{D} \rightarrow 2 \mathrm{D}$ parallel interpenetration, the other containing five interpenetrating 3D diamondoid nets.

The anionic nature of dca also leads to the possibility of anionic $\left[\mathrm{M}(\mathrm{dca})_{\mathrm{x}}\right]^{\mathrm{n}-}$ networks when $\mathrm{x}>2$ (for divalent metal ions). These require counter-cations to be included within the lattice, and we found that these counter-cations can template the network topology adopted by the surrounding $\left[\mathrm{M}(\mathrm{dca})_{\mathrm{x}}\right]^{\mathrm{n}-}$ coordination polymer. For example, with tetraphenylphosphonium cations 2D $(4,4)$ sheets are formed (Fig. 3a). ${ }^{[22]}$ When one phenyl group on the cation is changed to a methyl group, giving methyltriphenylphosphonium, the size of the cation is changed slightly, weak intercation supramolecular interactions within the structure are disrupted, and a 3D network is formed instead (Fig. 3b). Metal complexes can also be used as countercations, giving networks with $2 \mathrm{D}(6,3)$ or 3D $\alpha$-Po topologies. ${ }^{[23,24]}$

The importance of the M-NCN-M pathways in the magnetically ordered $\alpha-\left[M(d c a)_{2}\right]$ series led us to investigate the coordination chemistry of another ligand capable of such bridging, namely can (cyanamidonitrate (or nitrocyanamide), Fig. 1). Disappointingly, however, in a series of coordination polymers with the bridging co-ligands pyrazine and 4,4'-bipy the can anion either displayed monodentate coordination through the terminal nitrogen atom, or bridging via coordination of both the terminal nitrogen and a nitro oxygen atom, giving longer M-NCNNO-M pathways and a lack of long range magnetic ordering. [25]

More recently we have been investigating the chemistry of other SCAs, in particular the dicyanonitrosomethanide
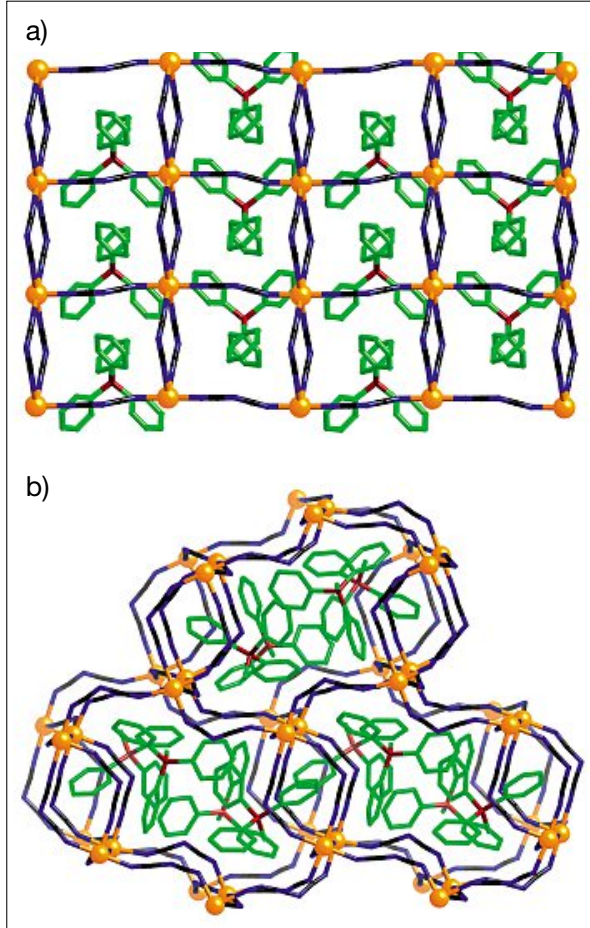

Fig. 3. (a) The 2D sheet structure of ( $\left.P h_{4} P\right)$ $\left[\mathrm{M}(\mathrm{dca})_{3}\right]$. (b) The 3D network of $\left(\mathrm{MePh}_{3} \mathrm{P}\right)$ $\left[\mathrm{M}(\mathrm{dca})_{3}\right]$.

(denm) anion (Fig. 1). This anion is notable for a number of reasons, in particular for its ability to undergo nucleophilic addition of water, alcohols or amines across one or (rarely) both of its nitrile groups. ${ }^{[3]}$ These generate whole new families of anions which can then themselves be used for a variety of applications, including coordination polymers. For example, reaction of denm and $\mathrm{Cu}^{\mathrm{II}}$ in methanol under solvothermal conditions gives the $2 \mathrm{D}$ coordination polymer $\left[\mathrm{Cu}(\mathrm{cmnm})_{2}\right]$ (Fig. 4), where cmnm (cyano[imino(methoxy)methyl]nitrosomethanide, Fig. 1) is formed by nucleophilic addition of methanol across one of the nitrile groups of denm. ${ }^{[26]}$ This system is also notable for the effect of the synthetic conditions on the product; similar reactions at room temperature on the benchtop

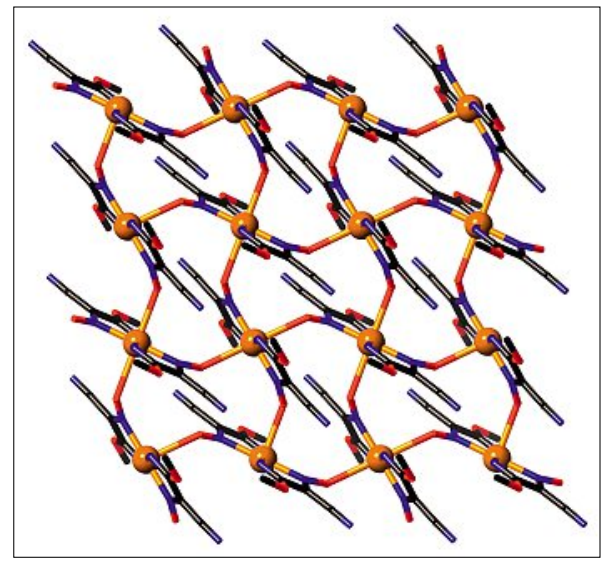

Fig. 4. The 2D coordination polymer $\mathrm{Cu}(\mathrm{cmnm})_{2}$. 
result in a discrete $\left[\mathrm{Cu}(\mathrm{cmnm})_{2}(\mathrm{MeOH})_{2}\right]$ complex being formed instead.

A particularly interesting system is obtained from the reaction of $\mathrm{Cu}^{\mathrm{II}}, 4,4^{\prime}$-bipy and ccnm (carbamoylcyanonitrosomethanide, Fig. 1), the product of nucleophilic addition of water to denm. ${ }^{[26]}$ Reaction in methanol results in magenta crystals of $\left[\mathrm{Cu}(4,4\right.$ '-bipy $\left.)(\mathrm{ccnm})_{2}\right] .4 \mathrm{MeOH}$, a $1 \mathrm{D}$ polymer. The polymeric chains consist of $\left[\mathrm{Cu}(\mathrm{ccnm})_{2}\right]$ species bridged by 4,4 '-bipy ligands; each ccnm ligand chelates to a single metal ion through its amide oxygen and nitroso nitrogen atoms (Fig. 5). The chains are then linked by extensive hydrogen bonding interactions between the ccnm anions and intercalated methanol molecules.

Similar reactions, but in mixed methanol/water solutions, give a different compound, [Cu(4,4'-bipy)(ccnm) $)_{2}$. This solvent-free phase displays a very different structure. Linear $\mathrm{Cu}(4,4$ '-bipy) chains are crosslinked into a 3D network by $\mathrm{ccnm}$ bridges, with the anion coordinating to one metal via its nitroso oxygen, and to another via its amide oxygen (Fig. 5). The most remarkable feature of this system, however, is that the solvated $1 \mathrm{D}$ polymer phase can be converted to the unsolvated 3D phase by grinding or even simply leaving the compound exposed so that the methanol evaporates from the crystals. This transformation from one structure to the other happens over six hours and can be followed under a microscope, despite the fact that the alignment of the $\mathrm{Cu}\left(4,4^{\prime}\right.$-bipy) chains in each structure is very different (all parallel in the solvated phase, but criss-crossing in the unsolvated phase), as is the coordinating mode of the ccnm anions (from chelating $\eta^{2}(N, \mathrm{O}) \mathrm{Cu}$ to bridging $\mu_{2}-\eta^{2}(\mathrm{O})$ $\mathrm{Cu}: \eta^{2}\left(\mathrm{O}^{\prime}\right) \mathrm{Cu}$ ').

Another small cyano anion that contains the amide functionality is cdm (carbamoyldicyanomethanide, Fig. 1). As for the solvated ccnm phase discussed above, hydrogen-bonding interactions between

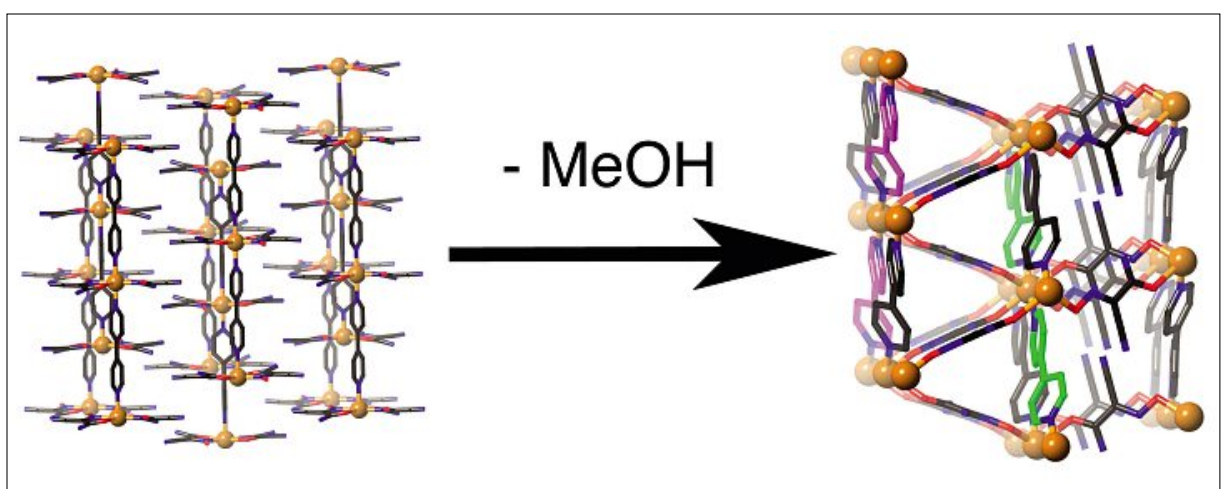

Fig. 5. The transformation upon desolvation of a 1D structure $\left(\left[\mathrm{Cu}\left(4,4^{\prime}-\text {-bipy }\right)_{2}(\mathrm{ccnm})_{2}\right] .4 \mathrm{MeOH}\right)$ with parallel $\mathrm{Cu}\left(4,4^{\prime}\right.$-bipy) chains (left, intercalated methanol not shown) to a 3D structure ([Cu( 4,4 'bipy $\left.\left.)_{2}(\mathrm{ccnm})_{2}\right]\right)$ containing inclined $\mathrm{Cu}(4,4$ '-bipy) chains (right, two inclined chains highlighted). the amide groups of adjacent anions, and/or between the amides and solvent molecules play very important roles in the structures. So much so, in fact, that usually the amide group prefers to participate in these interactions rather than coordinating. Thus, for example, reaction with $\mathrm{Cu}^{\mathrm{II}}$ and various monodentate pyridyl co-ligands results in the formation of $1 \mathrm{D}$ chains in which the metal atoms are bridged by pairs of $\mathrm{cdm}$ ligands coordinating through their nitrile nitrogen atoms. ${ }^{[27]}$ The amide groups then hydrogen bond to amide groups of adjacent cdm anions, and to intercalated methanol molecules, linking the chains into 2D sheets.

Like dcnm, although less common, the cdm anion can also undergo nucleophilic addition to generate new anions. Reaction of $\mathrm{K}(\mathrm{cdm})$ and $\mathrm{FeCl}_{3}$ in methanol results in production of the methanol addition product mcce (methyl 2-carbamoyl-2-cyano -ethanimidate, Fig. 1), and the subsequent formation of the $2 \mathrm{D}$ coordination polymer $\left[\mathrm{Fe}_{10}\left(\mu_{4}-\mathrm{O}\right)_{4}\left(\mu_{3}-\mathrm{OMe}\right)_{2}\left(\mu_{2}-\right.\right.$ $\mathrm{OMe})_{12} \mathrm{Cl}_{4}$ (mcce $\left.)_{4}\right] .[28]$ As the formula immcce anions chelated to the peripheries of each cluster bridge to adjoining clusters via the nitrile group, giving a $2 \mathrm{D}(4,4)$ sheet (Fig. 6). The structure is reinforced by $\mathrm{NH}$...nitrile hydrogen-bonding interactions between further chelated mcce anions, across the windows of the sheets.

While we have focussed here on the use of the small cyano anions for the construction of coordination polymers, we have also been putting these anions to great use in a number of other areas. A notable feature of nucleophilic addition products of denm is a great propensity to form metal clusters. These clusters show a significant variety of nuclearities, including both homo- and heterometallic species, and form for both transition metals and lanthanoids. ${ }^{[4]}$ Notable examples include 'lanthaballs' containing $\left[\mathrm{Ln}_{13}\left(\mathrm{CO}_{3}\right)_{14}\right]^{11+}(\mathrm{Ln}=\mathrm{La}, \mathrm{Ce}, \mathrm{Pr})$ cores, ${ }^{[29]}$ and $\mathrm{Dy}_{8}{ }^{[30]}$ and $\mathrm{Ln}_{2} \mathrm{Mn}_{2}{ }^{[31]}$ clusters shown plies, this structure contains $\mathrm{Fe}_{10}$ clusters;

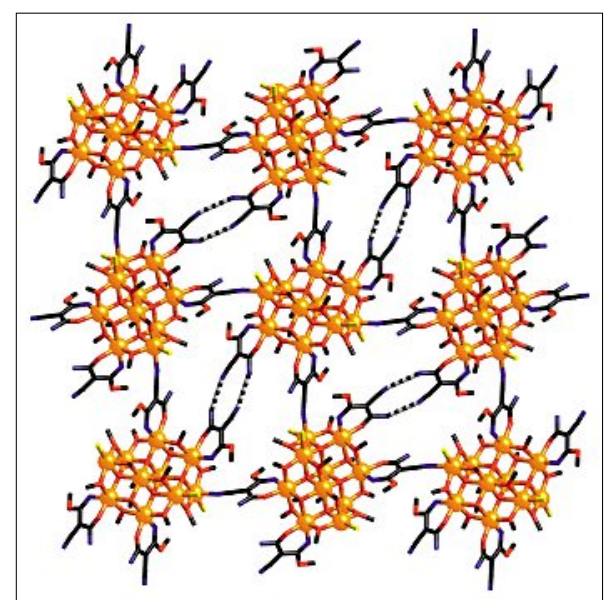

Fig. 6. A 2D coordination polymer of mcce, containing interlinked $\mathrm{Fe}_{10}$ clusters. Supporting hydrogen bonding interactions shown as striped bonds.

to display evidence of single molecule magnetism. Furthermore, the propensity of the cdm anion to form hydrogen bonds led to its use in the construction of new hydrogen bonding network structures, including the formation of unusual new 'Heterotape' motifs. ${ }^{[32,33]}$

Finally, anions such as dca, tcm, dcnm and ccnm can also be used to form new ionic liquids and plastic crystals. ${ }^{[34-37]} \mathrm{New}$ $\left[\mathrm{LnL}_{6}\right]^{3-}(\mathrm{L}=\mathrm{dcnm}, \mathrm{ccnm})$ species can be formed and these anions can also be used to form new ionic liquids, this time containing lanthanide complexes as the anions. ${ }^{[38]}$ Furthermore, it was found that a second polymorph of one these materials could be isolated by rapid cooling; this kinetically trapped phase had an even lower melting point than the more thermodynamically stable phase originally isolated. ${ }^{[39]}$

Received: March 14, 2013

[1] 'Chemistry of Pseudohalides', Eds. A. M. Golub, H. Köhler, V. V. Skopenko, Elsevier, Amsterdam, 1986

[2] J. Kohout, L. Jager, M. Hvastijova, J. Kozisek, J. Coord. Chem. 2000, 51, 169.

[3] S. R. Batten, K. S. Murray, Coord. Chem. Rev. 2003, 246, 103.

[4] D. R. Turner, A. S. R. Chesman, K. S. Murray, G. B. Deacon, S. R. Batten, Chem. Commun. 2011, 47, 10189.

[5] S. R. Batten, B. F. Hoskins, R. Robson, J. Chem. Soc., Chem. Commun. 1991, 445.

[6] S. R. Batten, B. F. Hoskins, B. Moubaraki, K. S. Murray, R. Robson, J. Chem. Soc., Dalton Trans. 1999, 2977.

[7] S. R. Batten, P. Jensen, B. Moubaraki, K. S. Murray, R. Robson, Chem. Commun. 1998, 479.

[8] M. Kurmoo, C. J. Kepert, New J. Chem. 1998, 22, 1515 .

[9] J. L. Manson, C. R. Kmety, Q. Z. Huang, J. W. Lynn, G. M. Bendele, S. Pagola, P. W. Stephens, L. M. Liable-Sands, A. L. Rheingold, A. J. Epstein, J. S. Miller, Chem. Mater. 1998, 10, 2552.

[10] J. L. Manson, C. R. Kmety, A. J. Epstein, J. S. Miller, Inorg. Chem. 1999, 38, 2552. 
[11] H. Hoshino, K. Iida, T. Kawamoto, T. Mori, Inorg. Chem. 1999, 38, 4229.

[12] J. L. Manson, E. Ressouche, J. S. Miller, Inorg. Chem. 2000, 39, 1135.

[13] R. Feyerherm, A. Loose, J. L. Manson, J. Phys.: Condens. Matter 2003, 15, 663.

[14] P. Jensen, D. J. Price, S. R. Batten, B. Moubaraki, K. S. Murray, Chem. Eur. J. 2000, 6, 3186 .

[15] P. Jensen, S. R. Batten, G. D. Fallon, B. Moubaraki, K. S. Murray, D. J. Price, Chem. Commun. 1999, 177.

[16] P. Jensen, S. R. Batten, B. Moubaraki, K. S. Murray, Chem. Commun. 2000, 793.

[17] P. Jensen, S. R. Batten, G. D. Fallon, D. C. R. Hockless, B. Moubaraki, K. S. Murray, R. Robson, J. Solid State Chem. 1999, 145, 387.

[18] P. Jensen, S. R. Batten, B. Moubaraki, K. S. Murray, J. Solid State Chem. 2001, 159, 352.

[19] P. Jensen, S. R. Batten, B. Moubaraki, K. S. Murray, J. Chem. Soc., Dalton Trans. 2002, 3712.

[20] S. R. Batten, B. F. Hoskins, R. Robson, Chem. Eur. J. 2000, 6, 156.

[21] S. R. Batten, A. R. Harris, P. Jensen, K. S. Murray, A. Ziebell, J. Chem. Soc., Dalton Trans. 2000, 3829.
[22] P. M. van der Werff, S. R. Batten, P. Jensen, B. Moubaraki, K. S. Murray, Inorg. Chem. 2001, 40, 1718.

[23] S. R. Batten, P. Jensen, B. Moubaraki, K. S. Murray, Chem. Commun. 2000, 2331.

[24] P. M. van der Werff, E. Martinez-Ferrero, S. R. Batten, P. Jensen, C. Ruiz-Perez, M. Almeida, J. C. Waerenborgh, J. D. Cashion, B. Moubaraki, J. R. Galan-Mascaros, J. M. Martinez-Agudo, E. Coronado, K. S. Murray, Dalton Trans. 2005, 285.

[25] A. M. Kutasi, D. R. Turner, P. Jensen, B. Moubaraki, S. R. Batten, K. S. Murray, CrystEngComm 2009, 11, 2089.

[26] A. S. R. Chesman, D. R. Turner, D. J. Price, B. Moubaraki, K. S. Murray, G. B. Deacon, S. R. Batten, Chem. Commun. 2007, 3541.

[27] D. R. Turner, S. R. Batten, Polyhedron 2010, 29, 333.

[28] D. R. Turner, S. N. Pek, J. D. Cashion, B. Moubaraki, K. S. Murray, S. R. Batten, Dalton Trans. 2008, 6877.

[29] A. S. R. Chesman, D. R. Turner, B. Moubaraki, K. S. Murray, G. B. Deacon, S. R. Batten, Chem. Eur. J. 2009, 15, 5203.

[30] A. S. R. Chesman, D. R. Turner, B. Moubaraki, K. S. Murray, G. B. Deacon, S. R. Batten, Dalton Trans. 2012, 48, 3751.
[31] A. S. R. Chesman, D. R. Turner, K. J. Berry, N. F. Chilton, B. Moubaraki, K. S. Murray, G. B. Deacon, Stuart R. Batten, Dalton Trans. 2012, 41,11402 .

[32] D. R. Turner, S. N. Pek, S. R. Batten, Chem. Asian J. 2007, 2, 1534.

[33] D. R. Turner, R. MacDonald, W. T. Lee, S. R. Batten, CrystEngComm 2009, 11, 298.

[34] D. R. MacFarlane, J. Golding, S. Forsyth, M. Forsyth, G. B. Deacon, Chem. Commun. 2001, 1430.

[35] S. A. Forsyth, S. R. Batten, Q. Dai, D. R. MacFarlane, Aust. J. Chem.2004, 57, 121.

[36] J. Janikowski, M. R. Razali, S. R. Batten, D. R. MacFarlane, J. M. Pringle, ChemPlusChem 2012, 77, 1039.

[37] J. Janikowski, M. R. Razali, C. Forsyth, K. M. Nairn, S. R. Batten, D. R. MacFarlane, J. M. Pringle, ChemPlusChem, 2013, 77, 1039.

[38] A. S. R. Chesman, M. Yang, N. D. Spiccia, G. B. Deacon, S. R. Batten, A.-V. Mudring, Chem. Eur. J. 2012, 18, 9580.

[39] A. S. R. Chesman, M. Yang, B. Mallick, T. M. Ross, I. A. Gass, G. B. Deacon, S. R. Batten, A.-V. Mudring, Chem. Commun. 2012, 48, 124. 